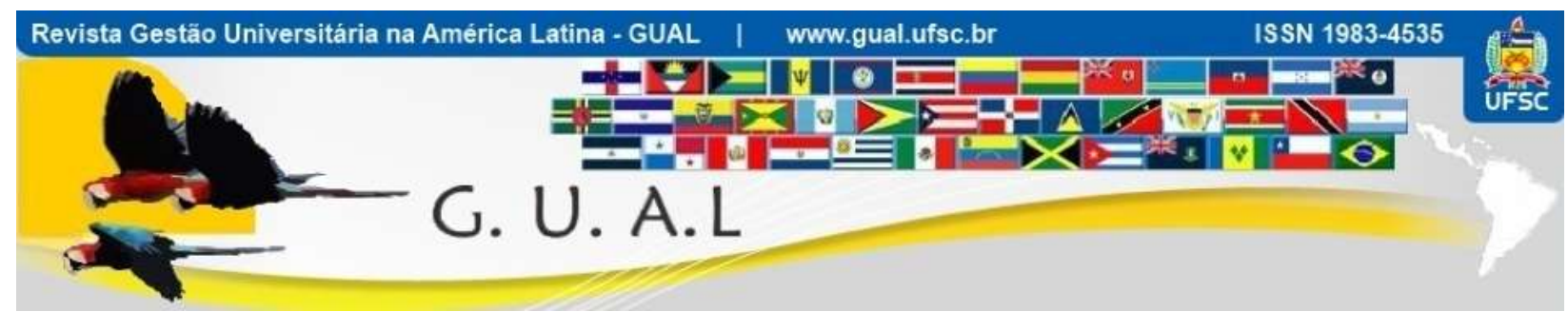

DOI: https://doi.org/10.5007/1983-4535.2021.e74825

\title{
A CONSTRUÇÃO DE UMA CULTURA DE TRANSPARÊNCIA PÚBLICA NA UNIVERSIDADE FEDERAL DO ESTADO DO RIO DE JANEIRO: UM ESTUDO DE CASO SOBRE A LEI DE ACESSO À INFORMAÇÃO
}

\author{
THE CONSTRUCTION OF A CULTURE OF PUBLIC TRANSPARENCY AT THE \\ FEDERAL UNIVERSITY OF THE STATE OF RIO DE JANEIRO: A CASE STUDY \\ ON THE ACCESS TO INFORMATION LAW
}

Daniele dos Santos Zeferino, Mestre https://orcid.org/0000-0001-9880-5234 danielezeferino@gmail.com Universidade Federal do Estado do Rio de Janeiro | Pró-Reitoria de Planejamento Rio de Janeiro | Rio de Janeiro | Brasil

Loreine Hermida da Silva e Silva, Doutora https://orcid.org/0000-0002-2332-7749 loreine.hermida@unirio.br Universidade Federal do Estado do Rio de Janeiro | Instituto de Biociências Rio de Janeiro | Rio de Janeiro | Brasil

Recebido em 17/junho/2020

Aprovado em 03/fevereiro/2021

Publicado em 01/maio/2021

Sistema de Avaliação: Double Blind Review

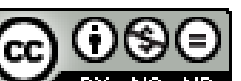

Esta obra está sob uma Licença Creative Commons Atribuição-Uso. 


\title{
RESUMO
}

A transparência nas universidades públicas, sob a ótica da Lei de Acesso à Informação (LAI), permite reafirmar sua finalidade como entidades voltadas à produção de conhecimento, além de fortalecer a democracia participativa e o controle social, na medida em que se divulgam informações de forma dinâmica e proativa aos reais interessados: o povo. O objetivo deste trabalho foi examinar como ocorreu o processo de implantação da transparência pública ativa estabelecida pela Lei de Acesso à Informação e quais as medidas necessárias ao cumprimento da legislação na Universidade Federal do Estado do Rio de Janeiro (UNIRIO). O estudo de caso, constituído de pesquisa documental e da aplicação de um instrumento do tipo questionário, revelou que a introdução da LAI na UNIRIO demandou uma série de adaptações organizacionais na instituição. A implantação bem sucedida da transparência foi conduzida por grupos de trabalho específicos que disponibilizaram um portal de acesso à informação eficaz e o cumprimento da legislação é possibilitado pelo estabelecimento de uma comissão permanente de transparência, com a participação de gestores e servidores que constroem coletivamente a cultura de transparência da Universidade.

Palavras-chave: Lei de Acesso à Informação. Transparência Pública. Transparência Ativa. Universidade Federal do Estado do Rio de Janeiro.

\begin{abstract}
Transparency in public universities, from the perspective of the Access to Information Law (LAI), allows to reaffirm their purpose as entities focused on the production of knowledge, in addition to strengthening participatory democracy and social control, insofar as information is disseminated dynamic and proactive way to the real interested parties: the people. The objective of this study was to examine how the process of implementing active public transparency established by the Access to Information Law occurred and what measures were necessary to comply with the legislation at the Universidade Federal do Estado do Rio de Janeiro (UNIRIO). The case study, consisting of documentary research and the application of a questionnaire-type instrument, revealed that the introduction of LAI at UNIRIO required a series of organizational adaptations at the institution. The successful implementation of transparency was conducted by specific working groups that provided an effective access portal to information and compliance with legislation is made possible by the establishment of a permanent transparency commission, with the participation of managers and employees who collectively build culture University transparency program.
\end{abstract}

Keywords: Access to Information Law. Public Transparency. Active Transparency. Universidade Federal do Estado do Rio de Janeiro. 


\section{INTRODUÇÃO}

O tema Transparência Pública vem ganhando visibilidade nos últimos anos, sobretudo a partir da aprovação de dispositivos legais que ordenam o controle na gestão pública. Uma pesquisa da Fundação Getúlio Vargas (FGV, 2014) constatou um aumento do clamor social pelo tema nos últimos anos, tendo como mote o combate à corrupção e à improbidade administrativa. $\mathrm{O}$ interesse popular pelo tema vem numa crescente, sobretudo após aprovação da Lei $\mathrm{n}^{\circ} 12.527$, de 18 de novembro de 2011.

A chamada Lei de Acesso à Informação (LAI) regula o acesso a informações de interesse particular ou coletivo que estejam sob guarda dos órgãos e entidades públicas. O acesso e a transparência de tais informações, de forma ativa e de forma passiva, já foram destacados por Bezerra e Borges (2012) como necessários ao controle social e à eficiência estatal. Já Cunha Filho e Xavier $(2014$, p. 8) salientam que a publicidade dos atos estatais é uma condição para a instituição da democracia participativa, pois “desprovido de informação, os cidadãos não podem realmente ser protagonistas na formação da vontade política do Estado". Marchezini (2017), por sua vez, ressalta que a transparência das informações é alicerce para o combate à corrupção e ao mau uso dos recursos públicos, devendo-se estimular a participação ativa da população como fiscalizadora nesse processo.

Para implementação e atendimento à LAI, nesses 8 anos de vigência da lei as instituições vêm continuamente se adaptando em termos de estrutura e demais recursos. Sobre isso, Michener, Contrera e Niskier $(2018$, p. 612) ressaltam que "uma lei de AI [acesso à informação] pode ser forte no papel, mas é notoriamente difícil garantir sua plena implementação e cumprimento". Cabem, então, algumas reflexões, que este trabalho pretende abordar: como ocorre o processo de planejamento da implantação de uma legislação como a LAI na prática? Que recursos foram e têm sido utilizados no cumprimento desse ordenamento jurídico? Que dificuldades podem interferir nesse processo?

Relatórios estatísticos do Sistema Eletrônico do Serviço de Informação ao Cidadão do Governo Federal (SIC) demonstram que no período de vigência da LAI (até maio de 2020), houve aumento dos pedidos de acesso à informação pública com o tema Educação Superior, que se constitui no quarto assunto mais pesquisado, com pouco mais de $6 \%$ de todos os pedidos.

Alguns trabalhos já foram realizados no sentido de estudar a aplicabilidade e cumprimento da LAI em universidades públicas. Jardim e Miranda (2015), por exemplo, 
focam na gestão arquivística necessária ao acesso à informação pública. Gama e Rodrigues (2016) tratam da demanda por transparência de informações contábeis nas universidades federais. Alguns estudos, como os de Maciel et al (2019) e Michener, Contrera e Niskier (2018), abordam a transparência passiva; outros (MONTEIRO, 2014; OLIVEIRA, 2017; RIBEIRO, 2017; RODRIGUES, 2013; ROSA; URBANETTO, 2014), discutem a transparência ativa em universidades federais; por fim, há trabalhos que versam sobre a implementação e atendimento à LAI de forma geral, como é o caso de Bufolin et al (2018), Lima (2019), Lucena et al (2014) e Oliveira et al (2013). Especificamente na universidade objeto desta pesquisa, Carvalho (2014) evidenciou os efeitos da LAI nas informações dos arquivos em um estudo de caso na Universidade Federal do Estado do Rio de Janeiro (UNIRIO).

Com outra delimitação, este trabalho se propõe a examinar como ocorreu o processo de implantação da transparência pública ativa estabelecida pela Lei de Acesso à Informação e quais as medidas necessárias ao cumprimento da legislação na UNIRIO. Cabe ressaltar que este estudo se diferencia de Carvalho (2014), pois abrange outros aspectos, além dos arquivos da Universidade. Ademais, em decorrência do tempo, foi lançada uma nova versão da página de acesso à informação da UNIRIO, sendo que a atualização de informações em sites de transparência pública é uma tarefa contínua.

Explorar o desenvolvimento da transparência pública em uma universidade é relevante principalmente por ser uma instituição que se propõe a oferecer uma formação profissional e crítica, de estímulo à produção do conhecimento e responsável por transformações sociais. Além disso, as universidades constroem grande massa documental e informacional (COSTA, 2016), de forma que a divulgação de suas informações pode chamar atenção da sociedade para o valoroso serviço público a que se propõe: a formação acadêmica e educação pública. Em resumo, "o dever de informar das instituições de ensino está relacionado com sua própria razão de ser", por se firmarem pelo diálogo (LOPES; GERALDES, 2017, p. 3).

Para atingir o objetivo do trabalho, conduziu-se um estudo de caso, constituído por pesquisa documental, a partir da análise sistemática da legislação associada, normatizações internas e site oficial da instituição pesquisada, e em seguida foi aplicado um instrumento tipo questionário para complementar a coleta de dados. Expondo esses resultados, após esta introdução, apresenta-se uma seção de referencial teórico, que abrange a importância do acesso à informação pública e destaca os principais itens da LAI, assuntos que nortearam a 
pesquisa. Evidencia-se aqui o enfoque da pesquisa na questão da transparência ativa. Após, descreve-se a metodologia da pesquisa escolhida para atingir os objetivos propostos. Em seguida, a seção de resultados mostra os achados da pesquisa, buscando aproximações com o referencial teórico apresentado. Finaliza-se com considerações finais e proposições de trabalhos futuros.

\section{REFERENCIAL TEÓRICO}

O referencial teórico que serve de base para o desenvolvimento deste trabalho envolve estudos sobre a importância do acesso à informação e da transparência de atos públicos bem como as principais determinações introduzidas com a LAI e como elas devem ser aplicadas.

\subsection{O ACESSO À INFORMAÇÃO E A TRANSPARÊNCIA PÚBLICA}

De forma resumida, o direito de acesso à informação pública pode ser entendido como a disponibilização de informações de interesse público ou particular, produzidas ou sob guarda do Estado (MARTINS, 2011). Já Heinen (2014) esclarece que o conceito de transparência pública é um pouco mais amplo, sendo relacionado à obrigatoriedade de que os atos de governo sejam claros para que o cidadão comum tenha condições de controle e participação social.

A transparência pública vem sendo estudada sob diferentes enfoques. Mendel (2009, pg. 3), por exemplo, pondera que "em 1990, havia uma visão predominante do direito à informação como uma medida de governança administrativa, ao passo que hoje este direito é cada vez mais considerado como um direito humano fundamental". Em um sentido mais amplo, Canela e Nascimento (2009, p. 5) afirmam que "não existe democracia plena se a informação está concentrada nas mãos de poucos", sendo que no caso de informações detidas pelo poder público, essas verdadeiramente pertencem ao povo.

Organismos internacionais vem há muito tempo se preocupando em normatizar a transparência pública no mundo. Destaca-se a Declaração Universal de Direitos Humanos da ONU, que em seu artigo 19 estabelece o direito de acesso à informação vinculado à liberdade de expressão: "todo ser humano tem direito à liberdade de opinião e expressão; este direito inclui a liberdade de, sem interferência, ter opiniões e de procurar, receber e transmitir informações e ideias por quaisquer meios e independentemente de fronteiras" (ONU, 1948). 
No Brasil, o direito de acesso à informação pública é previsto na Constituição Federal de 1988 (BRASIL, 1988, Art. 5, inciso XXXIII), que determina que:

todos têm direito a receber dos órgãos públicos informações de seu interesse particular, ou de interesse coletivo ou geral, que serão prestadas no prazo da lei, sob pena de responsabilidade, ressalvadas aquelas cujo sigilo seja imprescindível à segurança da sociedade e do Estado.

Esse direito se fundamenta como um direito instrumental (NÓBREGA, 2017), que serve à conscientização de outros direitos do cidadão, pois somente a partir do entendimento dessa prerrogativa, o cidadão estará apto a conquistar outros direitos e participar democraticamente da sociedade. Dito de outra forma, por Ribeiro (2017, p. 16), "sem acesso às informações, a participação da comunidade institucional, local e regional se dará em condições desiguais, e não será exercida a plenitude da gestão democrática nos colegiados, espaço de tomada de decisão".

Martins (2011) cita ainda outros benefícios do acesso à informação: possibilidade de fiscalização da máquina pública, com a participação popular no cenário político; o combate à corrupção, dada à transparência dos atos públicos, e; a contribuição para formação de cidadãos conscientes e politizados. Michener, Contreras e Niskier (2018, p. 613) ainda complementam que "o compromisso real com a transparência, afinal, representa o fornecimento de informações suficientes para tornar governos suscetíveis a críticas”, portanto, o acesso a informações fortalece o accountability governamental.

Pode-se afirmar que o direito de acesso à informação pública, preceituado desde a Carta Magna, precisava ser regulamentado por normatizações concretas posteriores, que especificassem procedimentos, prazos e sanções associadas a sua implementação na prática da administração pública (CANELA; NASCIMENTO, 2009). Nesse sentido, salienta-se o extenso rol de legislações brasileiras que buscaram, de alguma forma, abarcar o tema 'transparência pública', como bem elenca Oliveira (2017). Assim, mais de 20 anos se passaram da previsão constitucional até a aprovação da Lei de Acesso à Informação, destacada neste trabalho como a principal dessas legislações, e assunto da próxima subseção.

\subsection{A LEI DE ACESSO À INFORMAÇÃO}

A Lei de Acesso à Informação veio regulamentar o acesso à informação sob guarda da Administração Pública, mencionada na última subseção. Estão sujeitos à LAI todos os órgãos e entidades da Administração Pública brasileira, nos âmbitos federal, estadual e municipal, 
dos 3 Poderes, além dos Ministérios Públicos, Defensorias Públicas e Tribunais de Contas, incluindo autarquias, fundações públicas, empresas públicas, sociedades de economia mista e demais entidades controladas direta ou indiretamente pelo Estado (BRASIL, 2011).

Suas diretrizes estão apresentadas em seu Art. $3^{\circ}$ :

I - observância da publicidade como preceito geral e do sigilo como exceção; II - divulgação de informações de interesse público, independentemente de solicitações;

III - utilização de meios de comunicação viabilizados pela tecnologia da informação;

IV - fomento ao desenvolvimento da cultura de transparência na administração pública;

V - desenvolvimento do controle social da administração pública. (BRASIL, 2011, Art. $3^{\circ}$ ).

Desde a aprovação da LAI, alguns avanços puderam ser apontados em relação ao acesso à informação pública, como a adoção de práticas e mecanismos voltados à transparência, os quais se desdobraram em aumento dos pedidos de informação respondidos e, portanto, do volume de informações acessíveis à população (NÓBREGA, 2017).

Cabendo aos órgãos e entidades constituintes da Administração Pública a gestão documental do Estado e a organização de mecanismos para que interessados tenham acesso a esses documentos (BRASIL, 1988, Art. 216, $§ 2^{\circ}$ ), a LAI distingue dois tipos de transparência pública: a transparência passiva e a transparência ativa. A primeira é garantida pela criação de um Serviço de Informações ao Cidadão, que recebe e responde a solicitações do público; Já a transparência ativa significa a obrigatoriedade de publicação de um rol mínimo de informações pelas entidades, independente de pedido, segundo determinados requisitos (BRASIL, 2011).

No que tange à transparência ativa, Mendel (2009) destaca que a obrigação de divulgação mesmo sem solicitações, de forma proativa, está associado ao aumento da quantidade de informações disponíveis que guardem interesse público significativo. Michener, Contrera e Niskier (2018), por sua vez, evidenciam que a disponibilização de informações por transparência ativa contribui para desfazer uma 'cortina de papel', uma metáfora para as barreiras entre o cidadão e o poder público, que detém essas informações.

No âmbito do Poder Executivo Federal, o Decreto no 7.724, de 16 de maio de 2012 (BRASIL, 2012) instituiu os procedimentos necessários ao cumprimento da LAI nos órgãos e instituições públicas a ela subordinados. Este decreto traz em seu artigo $7^{\circ}$ as determinações de transparência ativa, com uma lista de informações de divulgação obrigatória. Além disso, o 
artigo $8^{\circ}$ traz requisitos de divulgação dessas informações, que envolvem a disponibilização de ferramentas de pesquisa, objetividade e fidedignidade das informações, linguagem clara, formatos de arquivo abertos, acessibilidade, bem como a existência de formulários e instruções para o SIC.

De forma mais especificada, a Controladoria-Geral da União, autoridade responsável pelo monitoramento da implementação da transparência pública no Poder Executivo Federal, divulga um Guia de Transparência Ativa para esses órgãos (GTA-CGU), que orienta para um padrão mínimo para divulgação dessas informações. O referido Guia atualmente está em sua sexta edição e contém uma lista de itens obrigatórios para divulgação, com a base legal a que atendem, recomendações e observações gerais (CGU, 2019).

Heinen (2014, p. 135) ressalta que "o rol de informações obrigatórias a serem divulgadas é exemplificativo. Cada ente público poderá ampliar esta lista, franqueando que outras informações sejam divulgadas pela via da transparência ativa". Complementando, Cunha Filho e Xavier (2014) afirmam que a participação de cidadãos como solicitantes de acesso à informação pública pode ser útil para o aprimoramento do serviço público, pois se entende quais são as informações (assuntos, ações do Estado, políticas públicas) cuja busca demonstra maior interesse do cidadão.

\section{METODOLOGIA}

Esta pesquisa buscou entender a dinâmica de fenômenos inseridos em uma organização: os processos de implantação e cumprimento da transparência pública ativa na UNIRIO. Por isso, adotou-se uma pesquisa descritiva e de abordagem qualitativa, mais adequada à solução do objetivo proposto, com a condução de um estudo de caso. Além disso, salienta-se que a pesquisa é de natureza básica, pois não se empenhou na solução específica para o problema (SILVA, 2004), visto que o prosseguimento de um plano de ação fica a cargo da instituição pesquisada, que tem autonomia em seus processos de gestão, conforme artigo 207 da Constituição Federal (BRASIL, 1988).

O objeto da pesquisa é a Universidade Federal do Estado do Rio de Janeiro, Instituição Federal de Ensino Superior mais recente do estado, segundo dados do Ministério da Educação, fundada em 1969. O principal fator que motivou a opção pelo estudo de caso na referida instituição foi a acessibilidade aos dados, dada a existência e manutenção de um site que detalha a condução dos trabalhos internos relativos à implantação da transparência 
pública. Segundo pesquisa de Rodrigues (2013), a UNIRIO foi a única dentre as instituições pesquisadas que apresentou detalhes sobre essas ações, o que também se configura como uma acertada ação de transparência.

A coleta de dados do estudo de caso foi constituída de pesquisa documental, complementada por um questionário aplicado a uma servidora responsável pela transparência organizacional na instituição. Na parte documental, serviram à pesquisa, além da análise sistemática da legislação associada, normatizações e relatórios institucionais, o site oficial da instituição pesquisada e a página de acesso à informação, no endereço http://www.unirio.br/acessoinformacao, acessado no mês de maio de 2020.

Buscando informações não disponíveis nos documentos, foi encaminhado e-mail à presidência da comissão responsável pela transparência organizacional da Universidade com um questionário de perguntas abertas sobre a transparência ativa. As perguntas versaram sobre o critério de divulgação de informações públicas, as possíveis mudanças de rotina de trabalho a partir do processo interno de implantação da LAI em seus setores, a rotina de atualização do site de acesso à informação e as dificuldades percebidas no processo.

O questionário é destacado por Gil (2008) como uma técnica que possibilita menores gastos com pessoal e permite que o pesquisado o responda em momento conveniente. Além disso, o uso de perguntas abertas oferece liberdade de resposta ao respondente, o que foi benéfico para o estudo, considerando que essas informações se adicionavam às já coletadas em documentos.

Gil (2002, p. 140) explica que em estudos de caso, a coleta de dados costuma ser fundamentada por mais de uma técnica, o que é essencial para garantir a fidedignidade de seus resultados, pois “dessa maneira é que se torna possível conferir validade ao estudo, evitando que ele fique subordinado à subjetividade do pesquisador".

Utilizou-se como técnica a análise de conteúdo, a partir de 2 categorias: (1) implantação da transparência ativa; (2) cumprimento da transparência ativa. A primeira categoria diz respeito às primeiras ações de atendimento às determinações da LAI, suas dificuldades e desafios; já em relação à segunda categoria, além de uma breve verificação do atendimento à LAI, que seguiu um Protocolo de Pesquisa, adaptado de um checklist presente no GTA-CGU (CGU, 2019), descreveram-se os procedimentos adotados para manutenção da divulgação das informações obrigatórias. Adicionalmente, foram verificados os requisitos de divulgação estabelecidos no art. $8^{\circ}$ do Decreto $n^{0} 7.724 / 2012$. 
Em toda análise buscou-se por triangulação de dados, principalmente com as respostas ao questionário, a fim de buscar convergências ou divergências em relação às demais informações coletadas de forma documental. Yin (2001, p. 120) salienta que o uso da triangulação é um "fundamento lógico para se utilizar várias fontes de evidências".

\section{RESULTADOS E DISCUSSÕES}

Esta seção visa apresentar os resultados do estudo de caso sobre transparência ativa, realizado na UNIRIO. Inicialmente, discorre-se sobre o planejamento e processos relativos à implantação da transparência; depois, mostra-se como a Universidade se organiza para o cumprimento da LAI, no que tange à transparência passiva.

\subsection{IMPLANTAÇÃO DA TRANSPARÊNCIA ATIVA}

Com a publicação da LAI em novembro de 2011, a primeira ação de transparência instituída pela Universidade foi a composição de um Grupo de Trabalho, por meio da Portaria UNIRIO no 305, de 16 de março de 2012 (UNIRIO, 2012b), responsável por planejar e coordenar a execução da LAI na UNIRIO. Esse grupo (denominado GT-LAI 1) foi formado por servidores da administração central da instituição e suas ações (registros de reuniões, documentos e apresentações) passaram a ser registradas na página http://www.unirio.br/proreitorias-1/proplan/grupo-de-trabalho-da-lei-de-acesso-a-informacao.

Com a publicação do Decreto ${ }^{0}$ 7.724/2012, e para embasar as atividades do GT-LAI 1, a Universidade publicou a Ordem de Serviço UNIRIO GR nº 4, de 25 de maio de 2012, com procedimentos institucionais para atendimento à LAI. Segundo essa normatização interna, a transparência ativa na instituição deve estar em conformidade com o Guia para Criação da Seção de Acesso à Informação nos Sítios Eletrônicos dos Órgãos e Entidades Federais, com a divulgação das informações obrigatórias em site específico e manutenção das informações pelas unidades organizacionais responsáveis (UNIRIO, 2012b, Art. $2^{\circ}$ ). Essa primeira versão do Guia, elaborado pela CGU, indicava um rol de 10 itens obrigatórios a comporem a página de acesso à informação das instituições (CGU, 2012).

Segundo os registros de reunião, as atividades do GT-LAI 1 se basearam em discutir e definir os processos necessários à implantação da LAI na UNIRIO. Cada membro do GT-LAI 1 ficou responsável pela validação de uma parte das informações obrigatórias que deveriam ser divulgadas na página de acesso à informação, conforme sua área de atuação. Assim, por 
exemplo, coube ao Departamento de Recursos Humanos divulgar as informações sobre os servidores; à Comissão de Licitações, apresentar os dados de licitações de contratos; à Coordenação de Comunicação Social, definir a lista de perguntas frequentes, e; de forma geral, durante as reuniões do GT-LAI 1, os membros indicavam as pendências para lançamento do site. Em seguida, cada área responsável validava as informações para pôr o site em funcionamento.

Algumas preocupações elencadas foram a necessidade de ter uma única e confiável fonte de informações; o desejado treinamento de pessoal para execução das tarefas de transparência; a atenção com a linguagem utilizada e apresentação das informações, e, não menos importante; a sensibilização da comunidade em relação ao assunto 'transparência'.

Como fruto das reuniões e apresentação do GT-LAI 1 destaca-se, ainda em 2012, a principal atividade de implantação da transparência ativa, ou seja, o lançamento da primeira página de acesso à informação da UNIRIO. Essa página de transparência, atualmente fora do ar, foi avaliada como um modelo para as demais universidades federais, atendendo plenamente à legislação (UNIRIO, 2018a), e posteriormente foi substituída por uma nova versão, conforme se detalhará adiante. Importante destacar que se manteve o registro de todas as atividades do grupo de trabalho que operacionalizou a implantação da LAI na Universidade, o que possibilitou esta pesquisa.

A Ordem de Serviço sobre procedimentos de atenção à LAI também indicou a constituição de uma comissão permanente com a finalidade de acompanhar a execução da legislação (UNIRIO, 2012a, Art. $1^{\circ}, \S$ único), sendo que o GT-LAI 1 teria vigência provisória e seria dissolvido com o funcionamento da referida comissão. Tal comissão foi criada em fevereiro de 2013 e denominada Comissão Permanente de Transparência Organizacional (CPTO), porém seu regulamento não foi logo aprovado e suas ações também não foram iniciadas de imediato, conforme se explicará adiante.

Cabe lembrar que as ações de transparência organizacional contaram como um objetivo estratégico contido no Plano de Desenvolvimento Institucional elaborado à época (UNIRIO, 2011), marco regulatório norteador das atividades de ensino, pesquisa, extensão da Universidade durante o quinquênio 2012-2016.

Para mais uma ação pontual, em agosto de 2015, um novo Grupo de Trabalho foi designado para continuidade dos trabalhos de coordenação da transparência na UNIRIO. O chamado GT-LAI 2 teve por finalidade, 
indicar quais informações deveriam ser revistas ou produzidas para atualização da página criada pelo grupo anterior, encaminhando a demanda para a unidade gestora responsável. Foram identificados as unidades que não possuíam páginas web no domínio unirio.br e ainda outras páginas desatualizadas e recomendadas as devidas providências (UNIRIO, 2018, p. $6)$.

Assim, o GT-LAI 2 foi responsável por uma atualização da página de acesso à informação já existente e propôs ainda que as demais atividades de transparência fossem oficialmente assumidas pela CPTO, visto que, como a atualização de informações pública é tarefa continuada, era indicado transferi-la à referida comissão em caráter definitivo, o que será detalhado na próxima subseção.

Constata-se que a implantação da transparência ativa na UNIRIO foi possibilitada pela construção coletiva de diferentes unidades organizacionais, a partir da atuação de dois grupos de trabalho. Oliveira et al (2013) observaram que a utilização de grupos de trabalho para tarefas específicas, como a implementação de uma nova norma é uma ação comum em outras universidades federais. A criação desses grupos de trabalho evidencia uma preocupação com resultados céleres e eficazes, enquanto a instituição de uma comissão permanente denota a atenção continuada em relação à efetividade da transparência pública na instituição.

\subsection{CUMPRIMENTO DA TRANSPARÊNCIA ATIVA}

Após o lançamento da página de acesso à informação, representando a implantação da transparência ativa na UNIRIO, as demais ações para o cumprimento da LAI tiveram o papel fundamental da CPTO. As atividades da comissão estão registradas no site http://www.unirio.br/proplan/comissao-permanente-de-transparencia-organizacional. Regulamento da CPTO, aprovado pela Resolução UNIRIO no 4.563, de 26 de novembro de 2015, dispõe sobre seu objetivo de definir e acompanhar as ações e políticas de transparência organizacional da Universidade (UNIRIO, 2015). A comissão é composta por servidores vinculados a unidades organizacionais de nível estratégico e tático, além de membros estudantis, sendo um conjunto representativo de toda comunidade universitária.

A presidente da CPTO enfatizou a importância de a comissão funcionar como uma instância de divulgação da legislação referente ao acesso à informação. Dada a participação de todas as unidades gestoras da Universidade, infere-se que as informações são multiplicadas a partir da comissão para os demais servidores que precisam lidar com a LAI em seu dia a dia. 
O Relatório de Atividades da CPTO (UNIRIO, 2018a) indica que em 2017 foi lançada uma nova página oficial de acesso à informação (http://www.unirio.br/acessoinformacao), com layout adaptado à acessibilidade. A página é acessada por link presente no portal principal da instituição e recebe atualizações no mínimo semanais, coordenadas pela presidência da CPTO.

No que tange à efetividade do cumprimento da transparência ativa na UNIRIO, observa-se na página de acesso à informação uma cuidadosa atenção ao Guia da CGU. Como mencionado, o GTA-CGU (CGU, 2019) indica um rol contendo 12 itens obrigatórios para divulgação: (1) Institucional; (2) Ações e Programas; (3) Participação Social; (4) Auditorias; (5) Convênios e Transferências; (6) Receitas e Despesas; (7) Licitações e Contratos; (8) Servidores; (9) Informações Classificadas; (10) Serviço de Informação ao Cidadão - SIC; (11) Perguntas Frequentes, e; (12) Dados Abertos, desdobrados em outros subitens.

A análise da página de acesso à informação demonstra a presença de todos os itens obrigatórios, porém com algumas informações incompletas ou não totalmente condizentes com a legislação e com o GTA-CGU. São casos de informações desatualizadas ou disponibilizadas parcialmente e links que remetem para páginas específicas das unidades, as quais não divulgam a informação de forma clara e objetiva. Em outras situações, há indicação para obtenção de informações por outros meios (telefônico, por exemplo), em desacordo com a LAI, pois os órgãos e entidades devem divulgar suas informações públicas em seção específica de seus sites (BRASIL, 2012, Art. $7^{\circ}, \S 1^{\circ}$ ), buscando agregar todas as informações obrigatórias em um único endereço, para facilitar o acesso.

Esse tipo de problema já fora identificado em pesquisas correlatas em outras Universidades. Oliveira (2017), por exemplo, explica que só atender ao Guia da CGU não é o suficiente, porque pode haver informações divergentes e desatualizadas. De toda forma, como a atualização é constante, tais falhas não estão detalhadas neste trabalho, pois podem ser facilmente corrigidas e num próximo acesso podem já estar retificadas.

Apesar dessas falhas pontuais, observou-se uma preocupação em incluir itens de informações não obrigatórias e de diferentes categorias, como normas de gestão de pessoas, tabela de remuneração de cargos comissionados e funções gratificadas, informação de acompanhamento de processos de sindicância em Processos Administrativos Disciplinares e dados de emendas parlamentares recebidas pela Universidade. Essa medida também foi 
executada por outras universidades, principalmente no item $\mathrm{n}^{\mathrm{o}} 1$, denominado 'Institucional' (OLIVEIRA, 2017).

Além isso, 7 novos itens foram incluídos: (Item 13) Acesso e Exceções, com orientações sobre informações pessoais e sigilosas; (Item 14) Sobre a Lei de Acesso à Informação, direcionado à página do governo federal sobre a LAI; (Item 15) Planos de Governança, com todos os planos estratégicos da Universidade; (Item 16) Comissões e Comitês, com sua apresentação e área de atuação; (Item 17) Boletins Internos, nos quais são publicados os atos oficiais da Universidade, de responsabilidade da Chefia de Gabinete da Reitoria; (Item 18) Acessibilidade, e; (Item 19) Carta de Serviços, que informa sobra os serviços prestados pela instituição e sua forma de acesso, em atenção ao Decreto $\mathrm{n}^{\circ}$ 9.094/2017.

Verifica-se que a inclusão desses itens vai ao encontro dos princípios de transparência, ao divulgar informações relevantes sob guarda da Universidade. Segundo a presidente da CPTO, os itens foram escolhidos por serem indicadores institucionais, frequentemente solicitados à Universidade.

Os requisitos de divulgação estabelecidos pelo Decreto $n^{0} 7.724 / 2012$ foram, em sua maioria, atendidos pela página de acesso à informação. $\mathrm{O}$ site apresenta ferramenta de pesquisa de conteúdo, linguagem de fácil compreensão, além de acessibilidade. Especificamente, em relação à acessibilidade, estima-se que o site é 90\% acessível, segundo a presidente da CPTO. A maioria das informações está em formato aberto, de fácil acesso. A divulgação de dados abertos, segundo a legislação, tem objetivos de facilitar a análise de informações presentes em planilhas e documentos de texto, por exemplo, sobretudo para uso por pesquisadores.

No que tange à autenticidade e integridade das informações, foi incluído um banner na página principal de acesso à informação, com a seguinte inscrição: "a qualidade das informações e a atualização dos dados dos serviços são de responsabilidade das unidades organizacionais que as oferecem. Cada unidade acadêmica e administrativa tem autonomia para criar e atualizar suas informações diretamente pelo sítio eletrônico correspondente". Essa sentença atende ao disposto na LAI de que "cabe aos órgãos e entidades do poder público, observadas as normas e procedimentos específicos aplicáveis, assegurar a: [...] II - proteção da informação, garantindo-se sua disponibilidade, autenticidade e integridade" (grifo nosso) 
(BRASIL, 2011, Art. $6^{\circ}$ ). Além disso, distribui a reponsabilidade pela fidedignidade das informações pelos gestores competentes, produtores da referida informação.

A preocupação com a autenticidade e precisão das informações prestadas introduziu uma mudança em termos de gestão. A presidente da CPTO ressaltou ser necessária uma transformação cultural para disponibilização de dados institucionais, com atualização pelo menos mensal da página de acesso à informação e contato realizado pela CPTO com vistas à devida atualização de informações com as unidades organizacionais responsáveis. Isso coaduna com o apontado por Carvalho (2014, p. 137-138), que afirma que "a cultura organizacional e informacional tem ligação profunda com a maneira que a informação é comunicada e disseminada na Instituição". Na análise da autora, a conscientização da importância da transparência deve ser feita numa ação de educação, de cima para baixo, ou seja, iniciando pelos gestores e passando aos subordinados. Essa forma de conscientização também se aproxima com a experiência da UNIRIO, em que os membros CPTO transmitem as informações para suas equipes, criando uma rede de transmissão da cultura de transparência.

Algumas ações institucionais de transparência ativa, destacadas no Relatório de Atividades da CPTO (UNIRIO, 2018) foram: estabelecimento de um servidor público de cada unidade, responsável pela atualização de seus respetivos sites com informações obrigatórias de transparência; adaptações em termos de acessibilidade, e; criação de páginas oficiais no domínio unirio.br para unidades organizacionais que não as possuíam.

Evidencia-se também a elaboração e publicação da Carta de Serviços ao Usuário, que “tem por objetivo informar aos usuários dos serviços prestados pelo órgão ou pela entidade do Poder Executivo federal as formas de acesso a esses serviços e os compromissos e padrões de qualidade do atendimento ao público" (BRASIL, 2017, Art. 11, §1º). A Carta de Serviços da UNIRIO, produzida por gestores e representantes das unidades organizacionais e organizada pela presidência da CPTO, atende a finalidade legal de concentrar os serviços oferecidos por toda a Universidade, simplificando a obtenção de informações por quaisquer interessados.

Todas essas ações resultam em um desempenho bastante positivo no que tange à transparência pública no Plano de Desenvolvimento Institucional da UNIRIO. O relatório mais recente da CPTO aponta que 75\% das ações de transparência previstas no plano foram integralmente concluídas em 2018, com mais 17\% delas parcialmente atingidas (UNIRIO, 2019). 
Apesar desses avanços, a presidente da CPTO apontou uma dificuldade para o cumprimento da LAI: ainda há desconhecimento dos servidores quanto à legislação. Segundo a servidora, após a compreensão da legislação, o principal desafio atual é a carência de recursos humanos para melhoria da qualidade da informação divulgada, com efetiva transparência. A esse respeito, Michener, Moncau e Velasco (2015, p. 16) comentam que a LAI introduz um "estabelecimento de um novo paradigma administrativo", o que demanda capacitação, capacidade de comunicação e eficiência dos servidores públicos.

Para sanar os problemas detectados pelo estudo, recomenda-se uma revisão da página de Acesso à Informação a partir das seguintes ações: disponibilização e atualização das informações inexistentes, incompletas ou defasadas; verificação do funcionamento e correção de links; investimento na área de tecnologia de informação, para aperfeiçoamento das páginas; exclusão de informações duplicadas. Possivelmente, um grupo de servidores devidamente capacitados poderia ser destacado para um trabalho contínuo de transparência.

Sugere-se atenção especial aos itens 5, 6, 7 e 8 da página de acesso à informação da UNIRIO, os quais contém informações financeiras, de receitas e despesas da instituição, objetos de interesse públicos, por estarem associados a gastos governamentais. A esse respeito, Gama e Rodrigues (2016) lembram que a transparência de informações contábeis e financeiras permite a identificação da aplicação dos recursos públicos, isto numa conjuntura em que os gestores relatam sua insuficiência para atendimento das demandas.

É bastante válido manter a acertada ação conduzida na lógica de implantação da transparência na Universidade: uma construção coletiva, de gestores e servidores de diferentes áreas. Mas, mais do que isso, os usuários devem sentir facilidade no acesso a essa informação, pois é para o cidadão que ela é produzida, portanto, "a via de mão dupla precisa ser construída, inaugurada e utilizada" (MONTEIRO, 2014, p. 61).

Os problemas e dificuldades verificados na pesquisa se aproximam dos desafios apontados por Rodrigues (2013), Monteiro (2014), Rosa e Urbaneto (2014), Ribeiro (2017), Oliveira et al (2013), frente à aplicação da LAI. Isso deixa claro que esses aspectos acabam por coincidir, independente da instituição.

Os resultados deste estudo também possibilitaram constatar uma evolução em relação à pesquisa sobre transparência ativa realizada em todas as Universidades Federais por Monteiro (2014, p. 46), na qual a UNIRIO obteve nota 5,3 numa escala de 0 (zero) a 10 (dez), sendo esse resultado superior à média das demais Universidades. Outra pesquisa mais recente, 
de Lima (2019) já aponta que a UNIRIO figura no $8^{\circ}$ lugar entre as 63 universidades federais pesquisadas, no que tange ao atendimento à transparência ativa, o que se aproxima dos resultados agora captados.

Infere-se que a elaboração, em 2017, de um novo portal de acesso à informação, com aperfeiçoamento dos mecanismos tecnológicos, demonstrou, além do cumprimento da lei, uma preocupação com a gestão da informação e com dois relevantes compromissos aludidos em sua missão e visão organizacionais: contribuição para o exercício pleno da cidadania e comprometimento com a transparência organizacional, explicitados em seu Estatuto (UNIRIO, 2018b).

\section{CONCLUSÃO}

Considerando os objetivos propostos nesta pesquisa, constatou-se o processo de implantação da transparência pública ativa na UNIRIO foi fundamentado pela instituição de grupos de trabalho específicos, que planejaram a página de acesso à informação oficial da instituição, possibilitando ações contundentes para o atendimento à legislação em relação à transparência ativa de forma eficaz, dentro do prazo estabelecido e com boa avaliação dos órgãos de controle externo.

O estabelecimento de uma comissão permanente de transparência foi igualmente benéfico para a instituição por subsidiar a proposição e manutenção de ações de transparência organizacional de modo constante e duradouro. A participação de servidores de diferentes níveis hierárquicos da organização permitiu a multiplicação dos conhecimentos sobre práticas de transparência para além dos limites da comissão, tendo seus efeitos reproduzidos em toda a Universidade.

Decorridos pouco mais de oito anos da vigência da LAI, verificou-se que a UNIRIO vem se esforçando para manter o atendimento à legislação com qualidade, apesar de serem indicados ajustes para o efetivo cumprimento da lei. Conclui-se que a divulgação ativa tem um alcance muito mais expressivo, pois atinge simultaneamente maior número de interessados, portanto, apresentando maior eficiência em termos de gestão. A despeito dos desafios, conclui-se que os passos mais substanciais já foram alcançados.

Essa pesquisa soma-se às demais que mostram o viés da transparência pública em universidades e apresenta como contribuições a possibilidade do uso de seus resultados como um diagnóstico da implantação e cumprimento da transparência na UNIRIO, que pode ser 
usado no planejamento do mesmo em outras instituições. Especificamente aplicada à UNIRIO, a pesquisa pode servir para nortear e aperfeiçoar ações gerenciais. O cumprimento da legislação, agora, se baseia na transformação de uma cultura de sigilo para uma cultura de transparência, e na consolidação desta.

Uma possibilidade de extensão do estudo é abordar a transparência sob a perspectiva dos usuários da página de acesso à informação. Além disso, outra possiblidade para trabalhos futuros seria o aprofundamento da pesquisa com outros servidores da organização, visando tornar a triangulação de dados mais rica e abrangente. Uma proposição para trabalhos futuros é o estudo da transparência passiva na instituição, que só vem sendo estudada sob o viés da arquivologia, e poderia ser observada da perspectiva da gestão organizacional. Com isso seria possível verificar o apontamento de Lima (2019), que revela que os resultados de transparência ativa e passiva não coincidem na mesma instituição, de forma que uma instituição transparente ativamente não necessariamente tem a transparência passiva forte.

\section{REFERÊNCIAS}

BEZERRA, Rafael Oliveira. BORGES, Loreci João. Análise das prestações de contas na internet da Universidade do Estado de Santa Catarina. Revista GUAL, v. 5, n. 1, p. 66-82, jan.-abr. 2012.

BRASIL. Constituição da República Federativa do Brasil de 1988. Brasília, 1988.

Disponível em: http://www.planalto.gov.br/ccivil 03/constituicao/constituicao.htm. Acesso em: 2 jun. 2020.

BRASIL. Decreto $\mathbf{n}^{\mathbf{0}} \mathbf{7 . 7 2 4}$, de 16 de maio de 2012. Brasília, 2012. Disponível em: http://www.planalto.gov.br/ccivil 03/ ato2011-2014/2012/decreto/D7724.htm. Acesso em: 5 out. 2014.

BRASIL. Decreto no 9.094, de 17 de julho de 2017. Brasília, 2017. Disponível em: http://www.planalto.gov.br/ccivil_03/_ato2015-2018/2017/decreto/D9094.htm. Acesso em: 14 jul. 2018.

BRASIL. Lei no 12.527, de 11 de novembro de 2011. Brasília, 2011. Disponível em: http://www.planalto.gov.br/ccivil 03/ ato2011-2014/2011/lei/112527.htm. Acesso em: 16 ago. 2014.

BUFOLIN, Darko Rodrigues; SILVEIRA-MARTINS, Elvis; MACHADO, Rafael Peres; PINTO, Rodrigo Serpa. A adequação das instituições federais de ensino superior gaúchas à Lei de Acesso à Informação. Revista Eletrônica Científica do CRA-PR, v. 5, n. 1, p. 69-80, 2018. 
CANELA, Guilherme; NASCIMENTO, Solano. Acesso à informação e controle social das políticas públicas. Brasília, DF: Andi, 2009.

CARVALHO, P. F. de. Os efeitos da Lei de Acesso à Informação na gestão das informações arquivísticas: caso da Universidade Federal do Estado do Rio de Janeiro. 2014, 182 f. Trabalho de Conclusão de Curso (Mestrado em Ciência da Informação) Universidade Federal Fluminense, Niterói, 2014.

CGU - Controladoria-Geral da União. Guia para criação da seção de acesso à informação nos sítios eletrônicos dos Órgãos e entidades federais. $1^{\mathrm{a}}$ versão. Brasília, 2012. Disponível em: https://www.gov.br/acessoainformacao/pt-br/lai-para-sic/guias-e-orientacoes/gta-6aversao-2019.pdf. Acesso em: 22 maio 2020.

CGU - Controladoria-Geral da União. Guia de transparência ativa para órgãos e

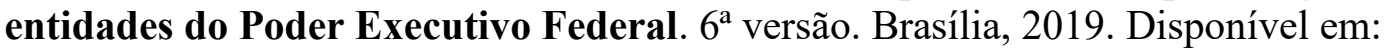
http://www.unirio.br/pro-reitorias-1/proplan/grupo-de-trabalho-da-lei-de-acesso-ainformacao/documentos-e-apresentacoes/guia-para-criacao-de-secao-de-acesso-a-informacaonos-sitios-eletronicos-dos-orgaos-e-entidades-federais-versao-1/view. Acesso em: 22 maio 2020.

COSTA, Gilvan Bernardo da. O direito de acesso à informação pública e a gestão da informação nas universidades: estudo de caso em uma instituição pública de ensino superior. Revista Interface, v. 13, n. 2, p. 79-96, ago.-dez. 2016.

CUNHA FILHO, M. C.; XAVIER, V. C. S. Lei de Acesso à Informação: teoria e prática. Rio de Janeiro: Lumen Juris, 2014.

FGV - Fundação Getúlio Vargas. Aumenta a demanda por transparência. O Globo, Infoglobo, 12 set 2014, p. 4. Disponível em: https://cutt.ly/wyX1XPX. Acesso em 14 maio 2018.

GAMA, Janyluce Rezende; RODRIGUES, Georgete Medleg. Transparência e acesso à informação: um estudo da demanda por informações contábeis nas universidades federais brasileiras. Transinformação, v. 28, n. 1, p. 47-57, jan.-abr. 2016.

GIL, A. C. Como elaborar Projetos de Pesquisa. 4 ed. São Paulo: Atlas, 2002.

GIL, A. C.. Métodos e técnicas de pesquisa social. 6 ed. São Paulo: Atlas, 2008.

HEINEN, J. Comentários à Lei de Acesso à Informação: Lei n ${ }^{\circ}$ 12.527/2011. Belo Horizonte: Fórum, 2014.

JARDIM, José Maria; MIRANDA, Vanessa Leite. A implantação da lei de acesso à informação nas universidades federais do Estado do Rio de Janeiro. In: ENCONTRO NACIONAL DE PESQUISA EM PÓS-GRADUAÇÃO EM CIÊNCIA DA INFORMAÇÃO, 16, 2015, João Pessoa. Anais..., João Pessoa: [ENANCIB], 2015. 
LIMA, Melina Pompeu de. As universidades públicas federais são transparentes? Uma avaliação à luz da Lei de Acesso à Informação. 2019, 132 f. Dissertação (Mestrado em Administração) - Universidade Federal Fluminense, Volta Redonda, 2019.

LOPES, Helen; GERALDES, Elen. Lei de Acesso à Informação nas universidades federais brasileiras: estado da arte e primeiros apontamentos. In: CONGRESSO BRASILEIRO DE CIÊNCIAS DA COMUNICAÇÃO - INTERCOM, 40, 2017, Curitiba. Anais..., Curitiba: Sociedade Brasileira de Estudos Interdisciplinares da Comunicação, 2017.

LUCENA, Danielle Silva de; FERREIRA, Kelly Lucy da Costa; ARAÚJO, Richard Medeiros de; PINHEIRO, Gilsemberg Gurgel. Lei de acesso à informação: uma leitura da implementação do Instituto Federal do Rio Grande do Norte. Revista Pensamento \& Realidade, v. 29, n. 1, p. 98-120, 2014.

MACIEL, Raoni Gonçalves; FONSECA, Platini Gome; DUARTE, Francisco Ricardo; SANTOS, Ernani Marques dos. Sistema Eletrônico do Serviço de Informação ao Cidadão (eSIC) e sua contribuição para a transparência: uma experiência gerencial em uma universidade federal. Perspect. ciênc. inf., Belo Horizonte, v. 24, n. 2, p. 143-164, jun. 2019.

MARCHEZINI, J. Informações acessíveis e participação popular são chaves contra a corrupção. Artigo 19. São Paulo, 18 dez. 2017. Entrevista à rádio CBN. Disponível em: https://cutt.ly/PyXhZqZ. Acesso em 12 jul. 2018.

MARTINS, P. L. Acesso à Informação: um direito fundamental e instrumental. Revista Acervo, v. 24, n. 1, p. 233-244, 2011.

MENDEL, T. Liberdade de informação: um estudo de direito comparado. 2. ed. Brasília: UNESCO - Organização das Nações Unidas para a Educação, a Ciência e a Cultura, 2009.

MICHENER, Gregory; CONTRERAS, Evelyn; NISKIER, Irene. Da opacidade à transparência? Avaliando a Lei de Acesso à Informação no Brasil cinco anos depois. Revista de Administração Pública, v. 52, n. 4, p. 610-629, 2018.

MICHENER, Gregory; MONCAU, Luiz Fernando; VELASCO, Rafael Braem. Estado brasileiro e transparência avaliando a aplicação da Lei de Acesso à Informação. Rio de Janeiro: FGV, 2015.

MONTEIRO, A. Aferição do grau de cumprimento às obrigações de transparência ativa constantes da Lei de Acesso à Informação por Universidades Federais do Brasil. 2014. 68 f. Trabalho de Conclusão de Curso (Mestrado em Administração) - Fundação Getúlio Vargas, Rio de Janeiro, 2014.

NÓBREGA, C. Os 5 anos da Lei de Acesso à Informação: uma análise de casos de transparência. São Paulo: Artigo 19, 2017.

OLIVEIRA, Andressa Cattafesta de. Acesso à informação pública e transparência ativa: um estudo do sítio institucional da Universidade Federal do Espírito Santo. 2017, 149 f. 
Dissertação (Mestrado em Gestão Pública) - Universidade Federal do Espírito Santo, Vitória, 2017.

OLIVEIRA, Clésia Maria de; GUILHERME, Crystiany Maria; LIMA, Natália Escobar Alioti; SIENA, Osmar; BARROS, Elaine Gemaque Gomes; PEDRUZZI JUNIOR, Aloir. Transparência e Acesso a informação: os desafios enfrentados na implementação da Lei ${ }^{\circ}$ 12.527 na Fundação Universidade Federal de Rondônia. In: COLÓQUIO DE GESTIÓN UNIVERSITARIA EN AMÉRICAS, XIII, 2013, Florianópolis. Anais... Florianópolis, UFSC, 2013.

ONU. Declaração Universal dos Direitos Humanos, 1948. Disponível em: http://unesdoc.unesco.org/images/0013/001394/139423por.pdf. Acesso em: 9 jun. 2018.

RIBEIRO, Ana Maria de Almeida. A necessária transparência pública na UFRJ para uma gestão democrática. Revista Práticas em Gestão Pública Universitária, ano 1, v. 1, n. 2, p. 1-27, jun.-dez. 2017.

RODRIGUES, G. M. Indicadores de "transparência ativa" em instituições públicas: análise dos portais de universidades públicas federais. Liinc em Revista, Rio de Janeiro, v.9, n.2, p. 423-438, 2013.

ROSA, Tatiana Costa; URBANETTO, Rosanara Pacheco. Lei de Acesso à Informação: análise dos portais eletrônicos das universidades públicas federais da região Sul do Brasil. Alexandria: Revista de Ciencias de la Información, ano 8, n. 11, p. 50-73, 2014.

SILVA, C. R. O. Metodologia e Organização do projeto de pesquisa (guia prático). Centro Federal de Educação Tecnológica do Ceará. 2004.

UNIRIO - Universidade Federal do Estado do Rio de Janeiro. Plano de Desenvolvimento Institucional 2012-2016. Rio de Janeiro: UNRIO, 2011. Disponível em:

http://www.unirio.br/proplan/pdi/plano-de-desenvolvimento-institucional-2012-2016. Acesso em: 28 maio 2020.

UNIRIO - Universidade Federal do Rio de Janeiro. Ordem de Serviço GR no 4, de 25 de maio de 2012. Rio de Janeiro, 2012a. Disponível em: http://www.unirio.br/proplan/ordem-deservico-004-25-05-12-lai. Acesso em: 10 mar. 2020.

UNIRIO - Universidade Federal do Estado do Rio de Janeiro. Portaria no 305, de 16 de março de 2012. Rio de Janeiro, 2012b. Disponível em: http://www.proplan.unirio.br/grupode-trabalho-da-lei-de-acesso-a-informacao/portaria-305-de-16-de-marco-de-2012/view. Acesso em: 10 mar 2020.

UNIRIO - Universidade Federal do Estado do Rio de Janeiro. Resolução UNIRIO n⿳0 4.563, de 26 de novembro de 2015. Rio de Janeiro, 2015. Disponível em: http://www.unirio.br/proplan/resolucao-4563-26-11-2015-regulamento-interno-cpto. Acesso em 10 maio 2020. 
UNIRIO - Universidade Federal do Estado do Rio de Janeiro. Comissão Permanente de Transparência Organizacional. Relatório de Atividades 2017. Rio de Janeiro, 2018a. Disponível em: http://www.unirio.br/proplan/Relatrioperidico2017CPTO.pdf. Acesso em: 3 jun. 2020.

UNIRIO - Universidade Federal do Estado do Rio de Janeiro. Estatuto da UNIRIO. Rio de Janeiro, 2018b. Disponível em: http://www.unirio.br/proplan/estatuto_unirio_2018.pdf. Acesso em: 6 jun. 2020.

UNIRIO - Universidade Federal do Estado do Rio de Janeiro. Comissão Permanente de Transparência Organizacional - CPTO. Relatório de Atividades 2018. Rio de Janeiro, 2019. Disponível em: http://www.unirio.br/pro-reitorias-1/proplan/Relatrioperidico2018CPTO.pdf. Acesso em: 3 jun. 2020.

YIN, R. K. Estudo de caso: planejamento e métodos. 2 ed. Porto Alegre: Bookman, 2001. 